\title{
Fostering Leadership Capacity among Black Male Achievers: Findings from an Identity-Based Leadership Immersion Program
}

\author{
Jasmine D. Collins \\ Doctoral Student \\ Education Policy, Organization and Leadership \\ University of Illinois at Urbana-Champaign \\ Cecilia E. Suarez \\ Assistant Professor \\ Agricultural Education and Communication \\ University of Florida \\ Cameron C. Beatty \\ Assistant Professor \\ Secondary and Higher Education \\ Salem State University \\ David M. Rosch \\ Assistant Professor \\ Agricultural Education \\ University of Illinois at Urbana-Champaign
}

\begin{abstract}
This study investigates the extent to which leadership capacity gains differ between participants of a leader development session targeted towards Black men and (a) other Black men who participated in racially and gender-diverse sessions; and (b) a racially proportionate sample of other men in racially and gender-diverse sessions. We employed an anti-deficit achievement framework within this research. Findings suggested that Black men who attended an all-Black Male session made gains similar or greater than each comparison group, even considering elevated capacity levels prior to participating. This study addresses important implications for understanding how engaging with same-race, same-gendered peers in formal leadership programs can support Black men in continuing to develop leadership capacity.
\end{abstract}

\section{Introduction}

Postsecondary institutions in the United States have long considered the development of the nation's future leaders among their core responsibilities (Cress, Astin, Zimmerman-Oster, \& Burkhardt, 2001; Dugan \& Komives, 2007). With today’s top employers placing increased emphasis on the ability of recent graduates to communicate effectively, collaborate in teams, solve problems, and make decisions (National Association of Colleges and Employers [NACE], 2013), colleges and universities play a prominent role in developing the leadership capacity the knowledge, skills, and behaviors commonly associated with leadership (Dugan, 2011) — of students who will soon enter the workforce. Moreover, they must consider how students with 
different identities experience and build capacity through campus engagement (Harper \& Quaye, 2014; Guthrie et al., 2013). As expressed by Guthrie and colleagues (2013), "Beyond changing demographics and university mission statements, evolution as a society will continue to be stagnant until the leadership talents of students from all backgrounds are engaged" (p.4).

In recent years, scholars have turned their attention to the leadership development of Black male achievers who actively engage in campus contexts (Amechi et al., 2016; Harper \& Quaye, 2007; Harper, 2009). Working to move beyond the rhetoric of "bad news" concerning enrollment and degree attainment rates of Black collegians (Harper, 2012), scholars have begun to recognize that Black men have unique needs and institutional experiences that must be further understood (Amechi et al., 2016; Harper, 2009). Existing research points to the potential of identity-based campus spaces such as Black affinity organizations to serve as sites of peer support, racial uplift and leadership growth (Harper \& Quaye, 2007; Sutton \& Kimbrough, 2001). If educators want to remain true to the call of educating all, not just some, of our students to lead in a diverse society, it is of paramount importance that higher education scholars, practitioners, and leadership educators consider how Black male spaces might enhance the ways Black men experience and practice leadership. To this end, this paper examines the ways in which participation in an identity-specific leadership program fosters the development of leadership capacity among Black males within a national, longitudinal, multi-institutional project.

\section{Literature Review}

Numerous studies in recent decades have shed light on high-impact practices, activities and interventions that contribute to the broad psychosical development of college students (Evans, et al., 2010; Harper \& Quaye, 2014; Kuh, 2011; Pascarella \& Terenzini, 2005); however, only a fraction of this research has been dedicated to understanding particular mechanisms of leadership capacity development. Further, much of this research centers on a generalized population of students at Predominantly White Institutions. As a result, theory and praxis of leadership development do not often utilize culture and identity as tools for relevancy and understanding, which may prove detrimental to students with underrepresented identities (Jones $\&$ Abes, 2013). Various studies have begun to delineate differences in the ways students perceive and practice leadership based on race and gender. This body of research suggests that women and students of color tend to place less value on labels and formal leadership postions than white male students, and gravitate to more collaborative and communal leadership practices aimed at achieving social change (Dugan, 2006; Kezar \& Moriarty, 2000; Rosch, Stephens, \& Collins, 2015). Given these findings, a need exists to examine how identity-specific leadership education initiatives may provide a differential effect within populations traditionally underrepresented in formal leadership programs - including Black men.

State of Formal Leadership Programs. The term formal leadership program refers to a collection of overarching leadership learning experiences intentionally designed for the purpose of developing or enhancing students' leadership knowledge, skills, and values (Dugan, 2011; Haber, 2011). The structure and content of leadership programs vary widely from context to context, including sequential, credit-bearing courses in a campus major or minor; one-time workshops; a series of lectures; off-campus retreats; and, more (Komives, et al., 2011). Currently, there are more than 2,000 curricular and co-curricular leadership programs for 
postsecondary students according the International Leadership Association onlinedirectory (www.ila-net.org).

Due to the wide variety of contexts, designs, purposes and modes of delivery of formal leadership programs, the empirical study of student participation in formal leadership programs is relatively sparse (Dugan, 2011; Owen 2012). This is particularly concerning when considering that the majority of formal leadership initiatives at United States campuses are considered new or emerging (Owen, 2012). Accordingly, there exists no foundational body of evidence to inform decisions about whether open (i.e., any student can participate) or targeted program models are most effective for particular student populations. Haber (2011) explains, "While an open program is desirable in many cases as it allows for the greatest accessibility, it may not address all needs of different student populations or different student roles" (p. 237). Given the evidence that social identity plays an important role in leadership development for college students (Guthrie et al., 2013; Jones \& Abes, 2013; Renn \& Ozaki, 2010), it is important to consider whether 'one size fits all' leadership programs are benefitting all students equally.

Black Male Students Thrive in Black Male Spaces. Recent research has begun to explore the role of identity-based spaces in the development of student leadership capacity (Arminio et al., 2000; Harper \& Quaye, 2007; Inkelas, 2004; Kezar \& Moriarty, 2000; Renn, 2007). In a study of leaders of identity-based campus organizations, Renn \& Ozaki (2010) found that students are often motivated to join identity-based campus organizations to "explore a psychosocial identity or participate in a group of like-others working for some common cause" (p. 19). Black male collegians, in particular, join Black affinity groups and other campus student organizations to address issues of injustice and to create venues of support.

Taking into consideration the feeling of obligation Black male student leaders feel to racially uplift the Black community on and off campus by engaging in leadership opportunities (Harper, 2012; Harper \& Quaye, 2007; Martin \& Harris, 2006), Harper and Quaye (2007) explored the motivations of Black male student leaders' commitment to campus student organizations. They found that Black male student leaders use both Black affinity groups and predominately White campus-wide student organizations as platforms for racial uplift and support for minoritized student interests. Sutton and Kimbrough (2001) also found that Black male student leaders' involvement on campus plays a crucial role in their overall undergraduate experience. These findings are consistent with other research that illustrate tendencies to resist individual approaches to leadership among students of color, opting more often for a group approach (Sutton \& Terrell, 1997; Harper \& Quaye, 2007; Arminio et al., 2000; Yamasaki, 1995; Renn \& Bilodeau, 2005a, 2005b).

In summary, Black male students who help lead Black affinity student organizations on campus become more grounded in, and shape the culture of, the student organizations they lead due to their (a) increased levels of commitment, (b) additional responsibilities, (c) heightened sense of identity, and (d) and propensity to work in group settings to achieve goals pertaining to the racial uplift of their campuses and communities. Hence, there are important implications for understanding how engaging with same-race, same-gendered peers in formal leadership programs can support these men in continuing to grow their leadership capacity. 


\section{Purpose and Research Question}

This study calls attention to the ways in which identity-specific leadership programming affects the leadership capacity of students, specifically Black men. To that end, this study investigates the extent to which leadership capacity gains exhibited by Black men who attended a LeaderShape Institute session devoted to their specific social identity differ from: (a) a matched sample of Black men in across other Institute sessions and (b) a racially representative sample of males who participated in other Institute sessions.

\section{Conceptual Framework of Black Male Leadership Development}

Harper's (2012) Anti-Deficit Achievement Framework served as an important guide for the development of this study. This framework seeks to combat commonly held notions about Black male collegians as at-risk, underprepared, and underacheiving by instead posing questions that seek to uncover how these students overcome obstacles, navigate campus cultures, and achieve success. Harper's (2012) Anti-Deficit Achievement Framework has been used to examine Black male student transition from high school to college (Harper, 2012), student of color trajectories in STEM (Harper, 2010), and Black male athlete's experiences (Cooper \& Hawkins, 2016). By examining the growth of participants of an exclusively Black male leadership program, this study sheds light on the successful outcomes of Black males actively engaged in a co-curricular experience intentionally designed with their success in mind.

Our conceptuatlization of leadership development within the context of leadership program participation used the "Ready-Willing-Able" model of leadership capacity (Burgoon, Rosch \& Keating, 2014), which clearly defines three contemporary post-industrial (Rost, 1993) aspects of effective leadership that serve to fortify one another. Within this model, "Ready" refers to one's capacity for leadership self-efficacy, or the confidence that one's leadershiporiented behaviors will lead to success (Hannah, Avolio, Luthans, \& Harms, 2008; Murphy, 1992). "Willing" is defined as the capacity for motivation to engage in leadership behaviors. Motivation to lead can stem from several sources: (a) Affective-Identity motivation(students' inclination and desire to think of themselves as leaders); (b) Social-Normative motivation (the sense of responsibility to lead their peers); and (c) Non-Calculative motivation (a self-centered calculation of how leading will result in their own personal benefit) (Chan and Drasgow, 2001); and (d) the motivation to engage in issues of social advocacy important to oneself (Nilsson, Marszalek, Linnemeyer, Bahner, \& Misialek, 2011). Lastly, to be "Able" is the capacity to exercise leadership skill, which encompasses Transformational, Transactional and Ethical skills. Transformational leadership skill is defined as the capacity to build authentic relationships, adhere to broad ethical standards, and create sustainable change while working with others within a group (Burns, 1978). Transactional leadership skill refers to the ability to create a motivating system of work through a system of structure and rewards within a team to achieve goals (Bass, 1998). Ethical leadership skill is the capacity to lead in ways that adhere to societal and organizational standards (Brown, Treviño, \& Harrison, 2005). Given the demands of today's employers, and the inclination of over $80 \%$ of co-curricular leadership programs to be built on post-industrial leadership foundations, (Owen, 2012, Rost, 1993), a conceptual model of leadership capacity that calls leaders to possess ethical values, work collaboratively with 
teammates in the pursuit of common goals, and engage in socially responsible actions and strategies is appropriate.

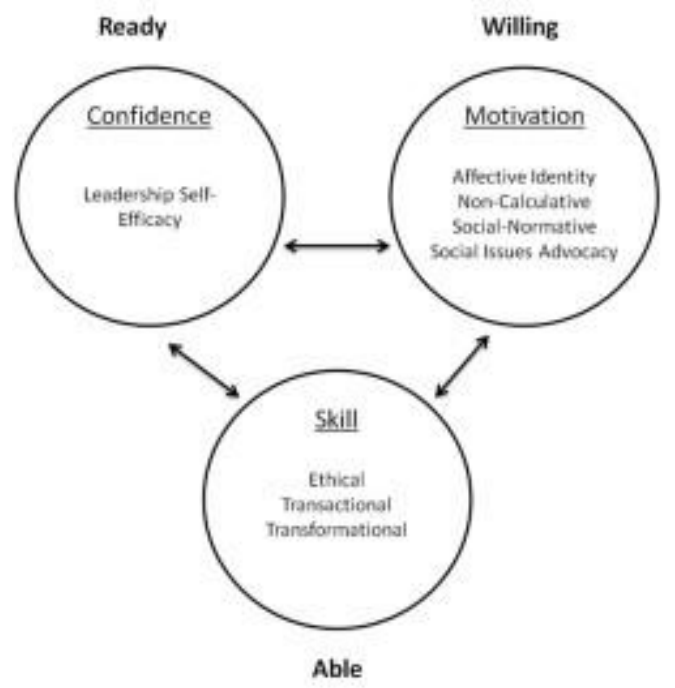

Figure 1. The "Ready, Willing, and Able” Conceptual Model of Leadership Capacity

\section{Methods}

Data Source and Population. This study utilizes data from a national, longitudinal, multi-institutional project designed to examine leadership development - specifically, leadership self-efficacy, motivation, and skill — among college students. All data were collected at LeaderShape Institutes, hereafter referred to as "sessions," sponsored by LeaderShape, Inc., a not-for-profit private organization that partners with postsecondary institutions to provide a highly structured six-day leadership immersion experience rooted in themes of community, inclusivity, integrity, and vision (www.leadershape.org). Through campus-based and national sessions (open to participants from any university and hosted directly by LeaderShape), more than 4,000 students in the United States, Canada, Mexico, and regions of the Middle East participate in one common transformational leadership curriculum annually.

All Black Male (ABM) Session. Disturbed by continuous occurrences of crime and mistreatment against Black men, the LeaderShape staff and Board of Trustees members saw the need to invite a group of Black men together to struggle with these ever pervasive societal issues. It was important to create a space to share their authentic selves while participating in the structured curriculum and tradition of a LeaderShape Institute session. After a year of soliciting buy-in from universities across the nation, more than 20 higher education institutions collectively sent 69 Black men to the all-African American Institute held in the summer of 2015 at a retreat center in rural Illinois. We refer to "Black men" rather than "African-American men within our research as not all participants in the ABM session self-identified as African-American. Within the $\mathrm{ABM}$ session, everyone including the on-site program coordinators, lead and small group facilitators, and all program participants identified as both Black and male. 
Data Collection. Our research was part of a larger national examination of educational outcomes associated with the LeaderShape Institute. An open call for study participation was sent electronically from a LeaderShape staff member to the program administrators of partner institutions in the fall of 2013 and 2014 resulting in 38 participating campus-based sessions in addition to 9 national sessions (where students from several campuses from across the United States sent students) across both years. While no Minority Serving Institutions or two-year institutions are represented in the sample, campuses in this comparison sample are diverse with respect to size, control, admissions selectivity, geographic region (U.S.) and faculty research output characteristics. Within these sessions, participants were invited to complete a pre-test survey prior to the beginning of the program's first day and a post-test immediately following the conclusion of the program on the sixth day. This ultimately produced a total of 47 unique sessions, while 2,405 students participated in both phases of data collection across both years.

Sample. Our criterion sample (Sample 1) consisted of Black men $(n=46$, representing $67 \%$ of the ABM participants) who completed both a pre-test post-test. Of these students, 8 (17\%) identified as freshmen, $16(34 \%)$ as sophomores, $12(26 \%)$ as juniors, $10(21 \%)$ as seniors, and $1(2 \%)$ as a graduate student. Thirty-five $(75 \%)$ reported being highly involved in student organizations, while $25(53 \%)$ reported holding positions of leadership within those organizations. To analyze the impact of the session on our sample of participants, it is important to make an appropriate comparison of this sample to other similar participants; in other words, control for the endogeneity of the error variance within our sample to the extent that this is possible. In this case, we compared our criterion sample to a group of Black men (Sample 2; $\mathrm{n}=47$ ) who had attended other sessions not specifically geared for this population who, as a group, were proportional to our sample of interest with respect to their year in school due to past research (Dugan \& Komives, 2010) identifying class year as a predictor of leadership capacity.

Given the size of our criterion sample, utilizing a restrictive process such as traditional propensity score matching, which matches individual participants with an individual comparison, would result in an unacceptable loss of sample size. Therefore, we used Coursened Exact Matching (CEM), which allows for the largest possible treatment pool within a set of participants given matching characteristics (Iacus, King, \& Porro, 2012), which is this case included participant gender and class year. We also created a comparison sample of racially diverse men (Sample 3) $(n=148)$ also matched by year in school using the same method. Given the size of our sample it was impractical to match our sample to other participants with regard to a variety of involvement characteristics relevant to measured leadership capacity (e.g., student organization involvement).

\section{Instrumentation and Data Analysis}

Our study was designed to measure the degree that social identity grouping (in this case, grouping of Black men) within structured leadership education affects student leadership capacity growth. We therefore assessed such growth in students' leadership skills, confidence in leading, and motivation to engage in leadership behaviors. To assess students' capacity within these areas, we used five different scales that incorporated a total of eight subscales. 
Leadership Skill. We measured leadership skill through three sub-scales: The Leader Behavior Scale (Podsakoff, MacKenzie, Moorman, \& Fetter, 1990), a popular and noncopyrighted 28-item instrument includes two sub-scales respectively focused on transformational $\left(\mathrm{LBS}_{\mathrm{F}}\right)$ and transactional $\left(\mathrm{LBS}_{\mathrm{A}}\right)$ leadership. A sample item for transformational behavior is, "I help other group members develop a team attitude and spirit among ourselves." A sample item for transactional leadership is, "I always give positive feedback when other group members perform well." Item responses have a 5-point Likert scale, ranging from "strongly agree" to "strongly disagree." We chose the LBS due to its use, for many years, as a broad measure of transformational leadership unassociated with the narrower Full-range Transformational Leadership Model and its respective Multifactor Leadership Questionnaire (Bass \& Avolio, 1997). The LBS has been in use for over 20 years as a psychometric tool (Yukl, 2010) in both business and education settings, with Cronbach reliabilities ranging from .71 to .89. Within our study, Cronbach alpha scores ranged from .72 to.87.

We also utilized the Ethical Leadership Scale (ELS), a 10-item measure designed to measure the degree to which participants incorporate ethical behavior into their leadership values and planned behaviors (Brown et al., 2005). The ELS is correlated with the Idealized Influence scale within the popular Multi-Factor Leadership Questionnaire (Bass \& Avolio, 1997), measuring aspects of transformational leadership. While ethical behavior and transformational leadership represent theoretically related but distinct concepts (Bass, 1998), confirmatory factor analysis shows that the ELS measures a leadership capacity distinct from transformational leadership (Brown, et al., 2005). Moreover, initial psychometric examination of the ELS showed no significant relationship with social desirability measures or social identity demographic factors (Brown, et al). Within our research, ELS Cronbach alpha scores were acceptable, ranging from .72 on the pre-test to .84 on the follow-up test.

Leadership Confidence. To assess students' confidence in leading, we utilized the SelfEfficacy for Leadership (SEL) scale, an 8-item measure of a person's confidence in engaging in leadership behaviors (Murphy, 1992). The SEL has been in use for 20 years in professional and educational environments and, like the LBS, has undergone extensive psychometric examination (Hoyt, 2005). A sample item is, "I know how to encourage good group performance." Item responses have a 5-point Likert-scale, ranging from "strongly disagree" to "strongly agree." Research has shown that internal reliability is good, i.e., above .76 (Murphy \& Ensher, 1999), and the scale has been shown to possess convergent and discriminant validity when used with measures of self-esteem and leadership experiences (Hoyt, 2005). Within our study, internal reliability scores ranged from .74 to .83 .

Leadership Motivation. Motivation to engage in leadership behaviors was measured using the Motivation to Lead (MTL) scale (Chan \& Drasgow, 2001), a 27-item measure equally divided across measures of affective-identity (AI), non-calculative (NC), and social-normative (SN) motivations to lead. The MTL assesses the degree to which people feel "called" to lead as well as the pressure they feel and energy they possess to engage in leadership behaviors. The AI scale concerns the degree to which an individual is personally drawn to leadership roles and includes items such as, "Most of the time, I prefer being a leader rather than a follower when working in a group." The NC scale concerns the degree to which a person avoids rationally calculating the individual costs and benefits of holding a leadership position and includesitems 
such as, "I never expect to get more privileges if I agree to lead a group." The SN scale is used to determine the degree to which a person leads due to a sense of duty or responsibility to others and includes items such as, "People should volunteer to lead rather than wait for others to ask or vote for them." Responses use a 5-point Likert scale, ranging from "strongly disagree" to "strongly agree." The scale has been used primarily in professional and public organizations and has alpha reliabilities ranging from a low of .65 for the NC scale to a high of .91 for the AI scale. The MTL has recently been extended to the field of higher education as a tool to measure student leadership development (Rosch, 2014). Within our study, Cronbach alpha scores ranged from a low of .65 to a high of .81 .

Social Issues Advocacy. Due to the LeaderShape curriculum focus, in part, on the application of social justice behaviors, we also included an adapted version of the Social Issues Advocacy Scale (SIAS) (Nilsson, Marszalek, Linnemeyer, Bahner, \& Misialek, 2011), recently designed to assess a person's motivation to publicly advocate for social issues considered both socially just and important to the person completing the measure. Aspects of politicaladvocacy (i.e., motivation to vote, lobby, or campaign for people or political issues) encompassed in the original scale were not included in the current study. Language within each item was also adapted for an educational environment, where phrases such as "I am professionallyresponsible to..." were changed to "I am personally responsible to..." Sample items within the SIAS include, "I am personally responsible to confront friends and colleagues who display signs of discrimination," and "I use social media to advocate for social issues that are important tome." While the scale has been in use for less time than the others, and therefore possesses fewer psychometric markers of strength, the original research conducted to create and validate the scale indicates an acceptable degree of convergent validity with measures of multicultural empathy, as well as discriminant validity when measured with items on self-esteem and lifesatisfaction. Within our study, Cronbach alpha scores were strong, ranging only from .84 within the pre-test to .88 within the follow-up test.

Data Analysis. To assess the degree to which our sample possessed similar pre-test leadership capacity to their respective comparison samples, we conducted independent sample ttests comparing incoming scores on the eight leadership capacity scales. To assess gains in capacity between samples, we first created "gain" scores representing the difference between incoming capacity and outgoing capacity. We then conducted a subsequent independent sample $\mathrm{t}$-test on these gain scores to examine differences in these gains by sample.

\section{Results}

Results of our analyses are shown in Tables 1 and 2. Table 1 shows the differences in pre-test scores of incoming leadership capacity and gains in capacity experienced over the course of the session between the criterion sample (Sample 1) and the matched sample of other Black males (Sample 2). Table 2 shows the differences in pre-test scores and leadership capacity gains between the criterion sample (Sample 1) and the matched sample of men from all races (Sample 3). Statistically significant differences are reported to .10, .05, and .01 alpha levels. Given past scholarship regarding statistical analysis within exploratory studies that suggest the identification of a .10 alpha level (Rosnow \& Rosenthal, 1989), we recognize the additional value this may 
provide to future researchers, given that such an alpha implies a $90 \%$ chance of non-random differences, and we describe such results as "marginally" significant.

Compared to other Black men, participants in the ABM session entered the program with elevated levels of transformational leadership skill, leadership self-efficacy, and affectiveidentity motivation to lead, with marginally significant elevated levels of social-normative motivation to lead. At the conclusion of the program, however, ABM participants made gains similar to the black male comparison sample, with statistically higher gains in social-normative motivation to lead. Compared to a broader sample of men consisting of all races, ABM session participants entered into their program with elevated levels of capacity in every area, while the gains they displayed after the program were smaller than their comparison sample in all areas of leadership skill and leadership self-efficacy, while gains were marginally significantly smallerin social issues advocacy motivation.

Table 1. Differences in Pre-test and Gain Scores Compared to Other Black Males

\begin{tabular}{|c|c|c|c|c|c|c|}
\hline & $\begin{array}{l}\text { Pre-Test } \\
\mu(\sigma)\end{array}$ & $\begin{array}{l}\text { Sample } 2 \\
\mu(\sigma)\end{array}$ & $\mathrm{t}$ & $\begin{array}{l}\text { Gain } \\
\mu(\sigma)\end{array}$ & $\begin{array}{l}\text { Sample } 2 \\
\mu(\sigma)\end{array}$ & $\mathrm{t}$ \\
\hline \multicolumn{7}{|l|}{ SKILL } \\
\hline Transformational & $8.07(0.83)$ & $7.80(1.12)$ & $2.05 * *$ & $0.71(0.88)$ & $0.77(1.02)$ & -0.29 \\
\hline Transactional & $8.34(1.37)$ & $7.70(1.59)$ & 1.35 & $0.55(0.97)$ & $0.78(1.25)$ & -1.01 \\
\hline Ethical & $8.19(1.00)$ & 7.95 (1.07) & 1.11 & $0.61(0.87)$ & $0.70(0.92$ & -0.47 \\
\hline \multicolumn{7}{|l|}{ CONFIDENCE } \\
\hline Self-Efficacy & $8.08(1.06)$ & $7.47(1.51)$ & $2.26 * *$ & $0.62(1.04)$ & $0.99(1.50)$ & -1.38 \\
\hline \multicolumn{7}{|l|}{ MOTIVATION } \\
\hline Social-Normative & 7.37 (1.09) & $6.96(1.16)$ & $1.74 *$ & $0.59(0.95)$ & $0.19(1.29)$ & $1.72 *$ \\
\hline Non-Calculative & $7.40(1.09)$ & $7.22(1.18)$ & 0.73 & $0.78(1.65)$ & $0.47(1.26)$ & 1.01 \\
\hline Affective-Identity & $6.90(1.31)$ & $6.14(1.46)$ & $2.64 * * *$ & $0.16(1.41)$ & $0.26(1.34)$ & -0.35 \\
\hline Social Issue & $7.78(1.25)$ & $7.57(1.25)$ & 0.83 & $0.78(0.94)$ & 0.69 (1.09) & 0.44 \\
\hline Advocacy & & & & & & \\
\hline
\end{tabular}


Table 2. Differences in Pre-test and Gain Scores Compared to Other Males

\begin{tabular}{|c|c|c|c|c|c|c|}
\hline & $\begin{array}{l}\text { Pre-Test } \\
\mu(\sigma)\end{array}$ & $\begin{array}{l}\text { Sample } 3 \\
\mu(\sigma)\end{array}$ & $\mathrm{t}$ & Gain $\mu(\sigma)$ & $\begin{array}{l}\text { Sample } 3 \\
\mu(\sigma)\end{array}$ & $\mathrm{t}$ \\
\hline \multicolumn{7}{|l|}{ SKILL } \\
\hline Transformational & $8.07(0.83)$ & $7.18(1.24)$ & $5.61 * * *$ & $0.71(0.88)$ & $1.22(1.13)$ & $-2.80 * * *$ \\
\hline Transactional & $8.34(1.37)$ & $7.33(1.73)$ & $3.58 * * *$ & $0.55(0.97)$ & $1.03(1.48)$ & $-2.56 * *$ \\
\hline Ethical & $8.19(1.00)$ & $7.43(1.32)$ & $3.57 * * *$ & $0.61(0.87)$ & $1.05(1.30)$ & $-2.64 * *$ \\
\hline \multicolumn{7}{|l|}{ CONFIDENCE } \\
\hline Self-Efficacy & $8.08(1.06)$ & $7.04(1.44)$ & $5.31 * * *$ & $0.62(1.04)$ & $1.38(1.43)$ & $-3.36 * * *$ \\
\hline \multicolumn{7}{|l|}{ MOTIVATION } \\
\hline Social-Normative & 7.37 (1.09) & $6.91(1.22)$ & $2.25 * *$ & $0.59(0.95)$ & $0.44(1.17)$ & 0.75 \\
\hline Non-Calculative & 7.40 (1.09) & $6.88(1.46)$ & $2.20 * *$ & $0.78(1.65)$ & $1.02(1.30)$ & -1.01 \\
\hline Affective-Identity & $6.90(1.31)$ & $6.33(1.75)$ & $2.39 * *$ & $0.16(1.41)$ & $0.48(1.59)$ & -1.23 \\
\hline Social Issue & $7.78(1.25)$ & $6.63(1.52)$ & $4.65 * * *$ & $0.78(0.94)$ & $1.13(1.23)$ & $-1.78^{*}$ \\
\hline Advocacy & & & & & & \\
\hline
\end{tabular}

Notes: $* p<.10, * * p<.05, * * * p<.01$

\section{Discussion}

Our results suggest participants of the ABM session came in highly skilled, and with higher leader self-efficacy, than both comparison groups and made marginally larger gains in social normative motivation to lead (the degree to which a person leads due to a sense of duty or responsibility to others) than the Black male matched sample. In addition, even though they entered with generally elevated capacities relative to the comparison samples, they made gains that were consistent with their peers. Within the context of quantitative survey methodology, this may be particularly noteworthy, as improvements in scores are statistically more difficult to show as the margin between pre-test scores and the maximum possible score decreases.

A marginally increased gain in social normative motivation to lead in ABM participants relative to their Black peers may also be particularly noteworthy, given the identity-based nature of the session. This finding indicates that placing Black men in a location to interact specifically with other Black men for the purpose of leadership capacity development may be a particularly effective way to help them develop a specific sense of responsibility to take on the roles of leadership amongst their peers. These results not only support past findings (e.g., Guthrie et al., 2013; Jones \& Abes, 2013; Renn \& Ozaki, 2010) that indicate the significance of social identity in students' different experiences, they also suggest a potential avenue for Black male achievement in the context of their leadership development. Given the salience of identity development in Black male development more generally (Harper \& Quaye, 2007), this finding may not be all that surprising.

Offering formal curricular and co-curricular leadership programs to university students is still a relatively new idea (Dugan, 2011) that is still emerging and growing (Owen, 2012) compared to many other educational initiatives. In an environment still emerging, one-size-fitsall services often play a primary role in program offerings, as they can cast a wide net for potential participants. This research project serves to highlight a leadership program geared 
specifically to Black men, a population consistently underrepresented in higher education (Amechi, et al., 2016) and in leadership development initiatives (Ospina \& Foldy, 2009). Our results suggest the potential that such a focus may be a helpful tool for their leadership development, particularly in high-achieving Black men.

\section{Implications}

This work offers important contributions to the research on student leadership development, the intersection of race and gender, and the importance of culturally relevant leadership education and opportunities. Whereas concepts of privilege, discrimination, and identities may not consistently be included when discussing "diversity in leadership", the ABM session worked to create a trusting and supportive environment where these issues could be focused on in relation to leadership capacity development.

This study can also serve as potential evidence for the need to diversify leadership curriculum and those who design such curricula to ensure that students from non-majority populations see themselves and hear their voice within the programs they attend. Suarez states, "voice provides a means to create avenues of communication to share realities of the oppressed" (2015, p. 42) and offers opportunities for students to insert themselves and see themselves in leadership curriculum. Culturally relevant leadership curriculum allows students the opportunity to potentially see someone who looks like them in a leadership role, but more importantly the opportunity to envision themselves as leaders.

\section{Limitations and Future Directions}

While this study does provide a new and unique insight into how participation in how an identity-specific leadership program fosters the development of leadership capacity among Black males, it does have its own set of limitations. Perhaps primarily, the ABM session participants were personally identified on their respective campuses for the session, and entered it with statistically elevated leadership capacity in some areas compared to other Black men - and perhaps most significantly in their affective-identity motivation to lead, which is directly related to their self-image as a leader. Our sample was not drawn randomly. Where these Black men different in important ways to their Black male peers? Future studies should examine the relevancy of this factor.

Participants of the study, once selected, attended the "all-African American Institute," and while they self-identified as such, this labeling may be exclusive to only American born, Black men. This categorization, while providing a de-generalization of the experiences of Black men, may have also served as an exclusionary tool if a participant identified as a Black man, but not an "African" or "American". For example, the identity of "Black" can have multiple subcategories for ethnicity or nationality, such as "Ethiopian" or Haitian American".

Similar to the limitation discussed above, the gender of "male" was generalized, and although participants self-identified as such, data on the varying power dynamics associated with a participant being a transgender male, queer male, or other identities not labeled as heteronormative were not collected. 
Lastly, our analysis relied solely on pre-tests and post-tests. Given the degree to which we define leadership capacity as the inclusion of leader self-efficacy and motivation to lead, longitudinal data collection is necessary to more accurately determine the effects of sessions. Without the ability to "practice" newly learned skills after the conclusion of the program, these current findings should be considered exploratory in nature.

\section{Conclusion}

The authors hope that by highlighting the first ever all Black male LeaderShape Session, critical connections of building leadership capacity amongst same-gendered and same-raced participants are established. FIf leadership development is a critical outcome of higher education, it is crucial to understand how to foster building leadership capacity in students from all racial and ethnic backgrounds, in order to best serve an increasingly diverse world.

\section{References}

Arminio, J. L., Carter, S., Jones, S. E., Kruger, K., Lucas, N., Washington, J., Young, N., \& Scott, A. (2000). Leadership experiences of students of color. NASPA Journal, 37(3), $496-510$.

Amechi, M. H., Berhanu, J., Cox, J. M., McGuire, K. M., et al. (2016). Understanding the unique needs and experiences of Black male subgroups at four-year colleges and universities. In S. R. Harper \& J.L. Wood (Eds.). Advancing Black Male Student Success From Preschool Through Ph.D. Sterling, VA: Stylus.

Burns, J. M. (1978). Leadership. New York, NY: Harper \& Row.

Center on Education and the Workforce (2013). Recovery: Job growth and education requirements through 2020. Washington, DC: Georgetown University.

Center for Higher Education Enterprise (2015). What works for Black male collegians. Columbus, OH: Ohio State University.

Colbeck, C. L., Campbell, S. E., \& Bjorklund, S. A. (2000). Grouping in the Dark: WhatCollege Students Learn from Group Projects. The Journal of Higher Education, 71(1), 60-83. doi:10.2307/2649282

Cooper, J. N., \& Hawkins, B. (2016). An anti-deficit perspective on black male student athletes'educational experiences at a historically black college/university. Race Ethnicity and Education, 19(5), 950-979. doi: 10.1080/13613324.2014.946491

Dugan, J. P. (2011). Research on college student development. In S. R. Komives, J. P. Dugan, J. E. Owen, C. Slack, W. Wagner \& Associates (Eds.), The handbook for student leadership development (2nd ed.). San Francisco, CA: Jossey-Bass. 
Gotanda, N. (2000). A critique of "Our Constitution is Color-Blind." In R. Delgado \& J. Stefancic (Eds.), Critical Race Theory: The cutting edge (2nd ed., pp. 35-38). Philadelphia, PA: Temple University.

Guthrie, K. L., Jones, T. B., Osteen, L. K., \& Hu, S. (2013). Cultivating leader identity and capacity in students from diverse backgrounds: ASHE Higher Education Report, 39 (4). Hoboken, NJ: Wiley.

Harper, S. R. (2012). Black male student success in higher education: A report from the National Black Male College Achievement Study. Philadelphia, PA: University of Pennsylvania, Center for the Study of Race and Equity in Education.

Harper, S. R. (2010). An anti-deficit achievement framework for research on students of color in STEM. In S. R. Harper \& C. B. Newman (Eds.), Students of color in STEM: Engineering a new research agenda. New Directions for Institutional Research (pp. 63-74). San Francisco: Jossey-Bass.

Harper, S. R., \& Patton, L. D. (Eds.) (2007). Responding to the realities of race. New Directions for Student Services, no. 120. San Francisco, CA: Jossey-Bass.

Harper, S. R., \& Quaye, S. R. (2007). Student organizations as venues for Black identity expression and development among African American male student leaders. Journal of College Student Development, 48, 127-144. doi:10.1353/csd.2007.0012

Iacus, S. M., \& King, G. (2012). How coarsening simplifies matching-based causal inference theory. (Working paper available at http://gking.harvard.edu/publications).

Keating, K., Rosch, D. M., \& Burgoon, L. (2014). Developmental readiness for leadership: The differential effects of leadership courses on creating "ready, willing, and able" leaders. Journal of Leadership Education, 13(3), 1-16.

Kezar, A., \& Moriarty, D. (2000). Expanding our understanding of student leadership development: A study exploring gender and ethnic identity. Journal of College Student Development, 41(1), 55-69.

Komives, S. R., Owen, J. E., Longerbeam, S., Mainella, F. C., \& Osteen, L. (2005). Developing a leadership identity: A grounded theory. Journal of College Student Development, 46, 563-611. doi: 611.doi:10.1353/csd.2005.0061

Martin, B. E., \& Harris, F. III. (2006). Examining productive conceptions of masculinities: Lessons learned from academically driven African American male student-athletes. Journal of Men's Studies, 14(3), 359-378. 
McGowan, B. (2013). Images of male friendships: An investigation of how African American undergraduate men develop interpersonal relationships with other men at a predominantly White institution. (Doctoral Dissertation). Indiana University, Bloomington. Retrieved from http://search.proquest.com.proxy.lib.iastate.edu/docview/1461462252/

National Association of Colleges and Employers. (2013). Job outlook 2013. Bethlehem, PA: National Association of Colleges and Employers.

Ospina, S., \& Foldy, E. (2009). A critical review of race and ethnicity in the leadership literature: Surfacing context, power and the collective dimensions of leadership. The Leadership Quarterly, 20, 876-896. doi:10.1016/j.leaqua.2009.09.005

Ospina, S., \& Su, C. (2009). Weaving color lines: Race, ethnicity, and the work of leadership in social change organizations. Leadership, 5, 131-170. doi:10.1177/1742715009102927

Owen, J. E. (2012). Findings from the Multi-Institutional Study of Leadership Institutional Survey: A National Report. College Park, MD: National Clearinghouse forLeadership Programs.

Rosnow, R. L., \& Rosenthal, R. (1989). Statistical procedures and the justification of knowledge in psychological science. American Psychologist, 44(10), 1276-1285.

Rosch, D. M., Stephens, C. M., \& Collins, J. D. (2015). Lessons that last: LeaderShape-related gains in student leadership capacity over time. Journal of Leadership Education, 15(1), 44-59. doi: doi: 1012806/V15/I1/R4

Rost, J. C. (1993). Leadership for the twenty-first century. Westport: CT: Praeger.

Smith, K. A., Sheppard, S. D., Johnson, D. W., \& Johnson, R. T. (2005). Pedagogies of Engagement: Classroom-Based Practices. Journal of Engineering Education, 94(1), 87101. doi: 10.1002/j.2168-9830.2005.tb00831.x

Suarez, C. E. (2015). Never created with nosotros in mind: Combating colorblind leadership education with cultural competency and intersectionality of identities. In Lozano. A. (Ed.) Latina/o College Student Leadership: Emerging Theory, Promising Practices. Lanham, Maryland: Lexington Books.

Sutton, E. M. \& Kimbrough, W. M. (2001). Trends in Black student involvement. NASPA Journal, 39(1), 30-40.

Sutton, E. M., \& Terrell, M. C. (1997). Identifying and developing leadership opportunities for African American men. In M. J. Cuyjet (Ed.), Helping African American men succeed in college. New Directions for Student Services, 80, 55-64. 


\section{Author Biographies}

Jasmine D. Collins jdcolli2@illinois.edu, is a doctoral student in the Educational Policy and Organizational Leadership Department at the University of Illinois at Urbana-Champaign, and serves as an instructor for leadership courses in the Agricultural Education Program.

Cecilia Suarez ccsuarez7@ gmail.com, is an Assistant Professor in the Department of Agricultural Education and Communication at the University of Florida.

Cameron C. Beatty cbeatty@salemstate.edu, is an Assistant Professor in the Secondary and Higher Education Department at Salem State University. His research explores the leadership identity development of students of color at predominately whiteinstitutions.

David M. Rosch dmrosch@illinois.edu, is Assistant Professor in the Agricultural Education Program at the University of Illinois at Urbana-Champaign, where his teaching and research is focused on the leadership development of emerging adults. 